\title{
MeteoGlosario Visual
}

\section{UN DICCIONARIO ILUSTRADO DE METEOROLOGÍA ONLINE PUBLICADO POR AEMET}

\section{EL EQUIPO DEL METEOGLOSARIO VISUAL}

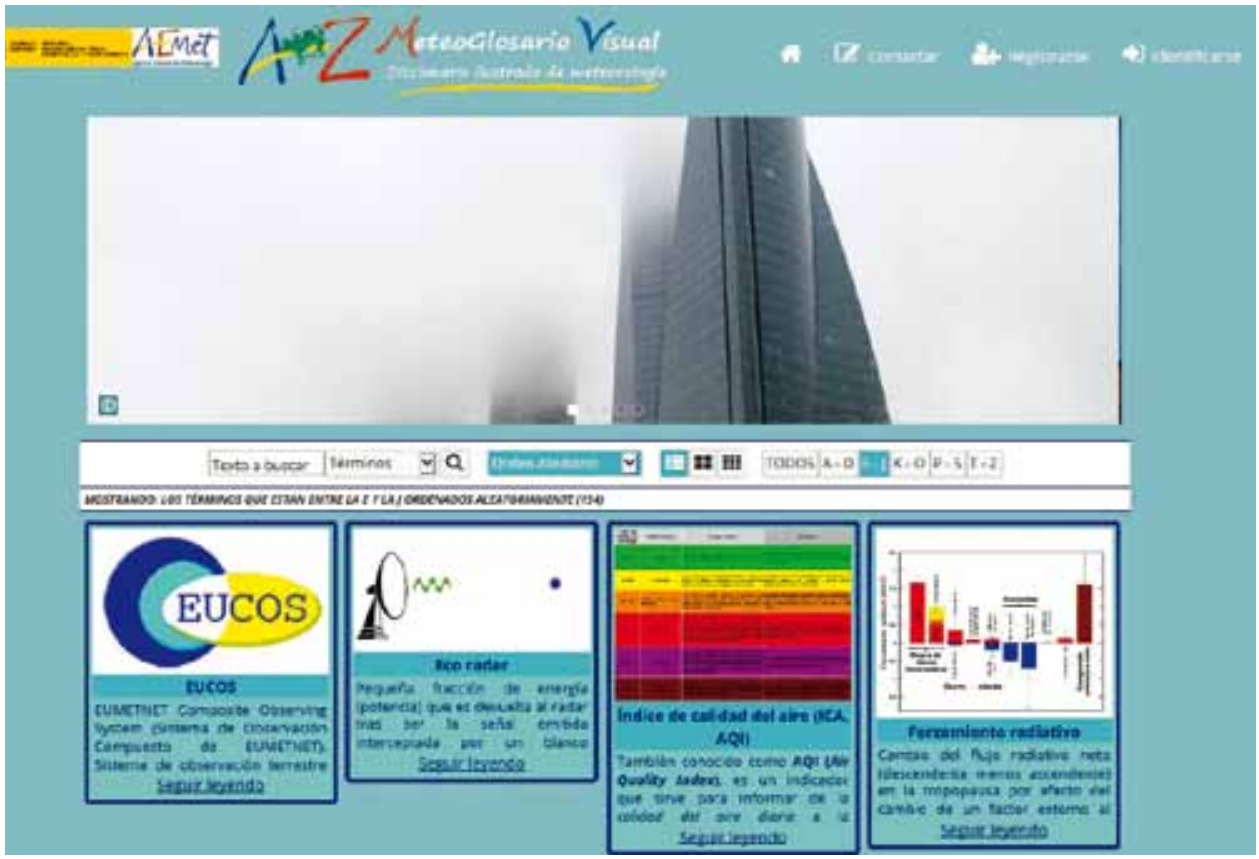

El lenguaje abre las puertas del conocimiento. $Y$ también sabemos lo importante que es llamar a las cosas por su nombre. Los conceptos con nombre propio definidos mediante unas pocas palabras son más fáciles de comprender, asimilar e interconectar entre ellos. Por otro lado, las imágenes pueden complementar en gran medida esas definiciones contribuyendo a su mejor comprensión. $Y$ sin duda, tanto los vocablos asociados a los conceptos, como sus definiciones o las imágenes que usamos para describirlos pueden ser bellos en si mismos y la belleza nunca está de más.

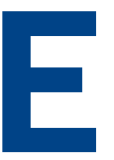

n la comunidad meteorológica internacional existen diversos glosarios, del latín glossarium, palabra masculina que según la Real Academia Española es un "Catálogo de palabras de una misma disciplina, de un mismo campo de estudio, de una misma obra, etc., definidas o comentadas". Algunos, los más conocidos y de mayor prestigio son el de la American Meteorological Society, Meteorology Glossary (glossary.ametsoc.org), en inglés, o el International Meteorological Vocabulary de la Organización Meteorológica Mundial accesible en diversos idiomas, junto a otras definiciones, a través de la herramienta Meteoterm (public.wmo.int/en/resources/meteoterm). En el campo vecino de la nivología destaca el glosario de la European Avalanche Warning Services, (www.avalanches.org), también multilingüe. Este último glosario tiene como particular que las definiciones van acompañadas de imágenes. También Météo-France tuvo durante unos años un glosario meteorológico acompañado de ilustraciones. A raíz de la observación de este glosario surgió hace unos pocos años en AEMET la idea de realizar un glosario visual de meteorología en español, con posterior traducción al resto de las lenguas oficiales en España. Es decir, un glosario que para cada uno de los términos incluyera por lo menos una imagen que podría ser una fotografía, un esquema, un gráfico o una ilustración.

El resultado de un equipo de profesionales de AEMET (se citan sus nombres en el apartado Sobre Nosotros del glosario) durante más de dos años de trabajo ha sido el MeteoGlo- sario Visual (meteoglosario.aemet.es), al que se puede acceder desde su página web, que fue presentado al público en la sede central de la Agencia en Madrid el pasado 23 de marzo, Día Meteorológico Mundial. El día de la presentación el MeteoGlosario Visual incluía casi 700 términos y más de 1200 imágenes. Tal cantidad de material ha sido el resultado de una concienzuda selección de vocablos a definir, de la redacción cuidadosa de sus definiciones y de la búsqueda o elaboración expresa de imágenes que sirvieran para ilustrarlos.

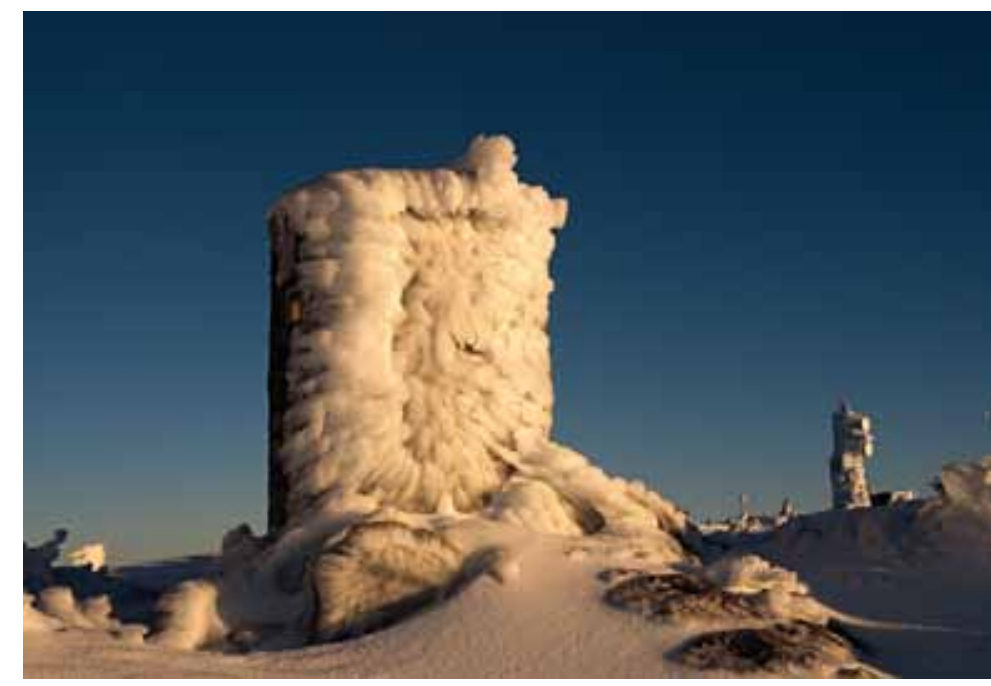

Cencellada. Autor: Rubén del Campo 


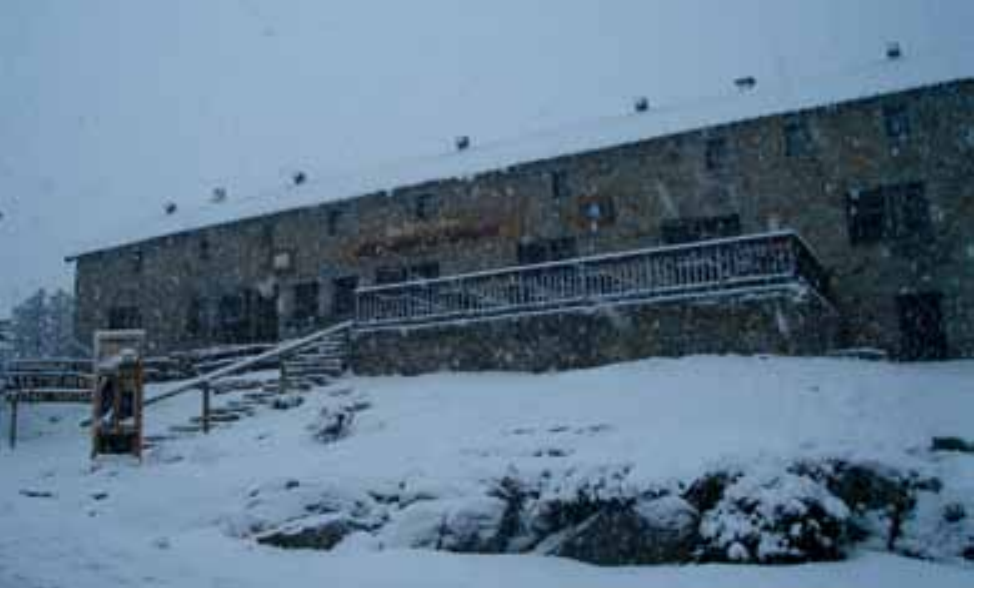

Nieve. Autor: Ramón Pascual

Como punto de partida para la elección de los términos a incluir se analizaron los contenidos presentes en la página web de AEMET (www.aemet.es) con el fin de extraer aquellos términos que pudieran no ser del conocimiento del público en general. Este proceso ha generado la inclusión de términos no relacionados directamente con la meteorología pero sí con la ciencia y la técnica y el servicio público vinculados con ella.

Una de las particularidades de este glosario es que algunas de sus ilustraciones son creaciones ex profeso, preparadas por tres personas de AEMET, con especiales dotes artísticas.

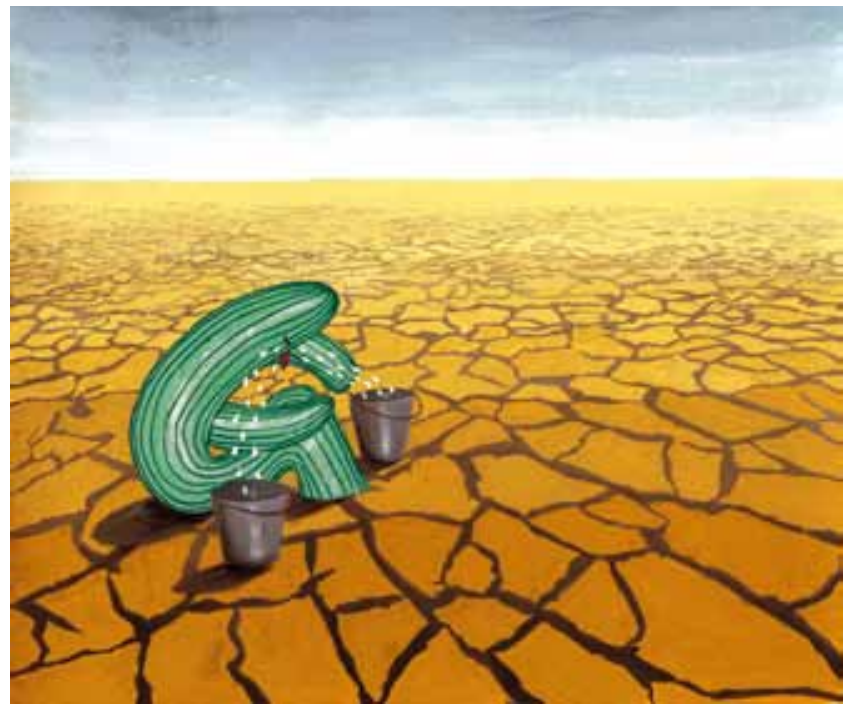

Sequía. Autor: Gabriela Cuevas

También es muy destacable el soporte en el cuál se presenta el glosario: una atractiva página web desarrollada por un informático de AEMET por la cuál es muy sencillo navegar y visualizar tanto las definiciones como las imágenes asociadas. Otro elemento a destacar es la funcionalidad de "términos relacionados" que se contempla la web: para cada uno de los términos del glosario existe un conjunto de otros términos del propio glosario, de número variable, que se han considerado básicamente relacionados con el primero.
Naturalmente, toda obra individual o colectiva es susceptible de mejora o ampliación. El equipo que ha creado el MeteoGlosario Visual es consciente que las diferentes partes del mismo pueden modificarse desde el mismo momento de su presentación, por tanto es una herramienta abierta, preparada para añadir nuevos términos, pulir o ampliar las definiciones, incrementar el número de imágenes o realizar las sustitución de las actuales por otras mejores, así como de llevar a cabo mejoras en la propia página web. Para ello parte del equipo creador sigue a cargo de la gestión de la herramienta y cuenta explícitamente con las aportaciones que los usuarios del glosario quieran hacer, sean profesionales de la meteorología, aficionados o público en general.

La preparación del glosario en su conjunto ha sido fruto de un intenso debate de dos años entre los miembros del equipo de trabajo, apoyado por la consulta a multitud de referencias bibliográficas citadas en la web del glosario, que además ha contado con numerosas aportaciones de personas externas al grupo, sean profesionales de AEMET o miembros de otras instituciones. Hemos querido hacer constar en los agradecimientos estas colaboraciones que hemos recibido. Un aspecto singular del glosario es que en él se han introducido los nombres y las siglas de diferentes organizaciones, instituciones, asociaciones, redes o proyectos relativamente poco conocidos pero que con una cierta frecuencia aparecen en documentos generados por AEMET o son de dominio público. En este sentido, este glosario tiene también un cierto carácter enciclopédico.

En resumen, desde AEMET creemos que el MeteoGlosario Visual es una herramienta amigable y útil que permite conocer, al menos en un primer nivel, el significado de muchos términos y expresiones que se usan comúnmente en meteorología y ciencias afines y también profundizar algo más en el conocimiento de esta relativamente moderna ciencia en su conjunto.

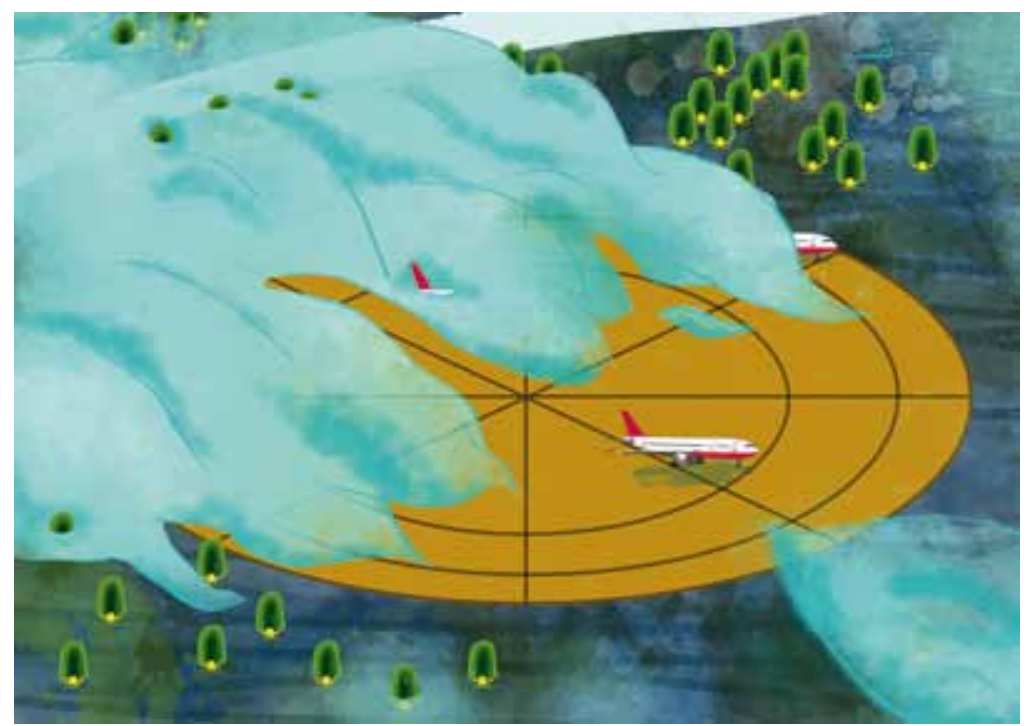

Visibilidad predominante. Autor: Julio Aristizábal 